2017-09-27

\title{
Auditions and stress
}

\section{Matthews, John}

http://hdl.handle.net/10026.1/10433

10.1080/20567790.2017.1377931

Stanislavski Studies

Informa UK Limited

All content in PEARL is protected by copyright law. Author manuscripts are made available in accordance with publisher policies. Please cite only the published version using the details provided on the item record or document. In the absence of an open licence (e.g. Creative Commons), permissions for further reuse of content should be sought from the publisher or author. 


\section{Audition and Stress}

\section{John Matthews and Victor Ladron de Guevara}

The canonical techniques of actor training associated with Stanislavski's own practice and writings have resulted in a dominant paradigm which, arguably, predominates within UK drama school training. The present article is the first part of a series of papers which aims to investigate this paradigm through the analysis of significant events of the audition process for the undergraduate Acting programme at the newly formed Plymouth Conservatoire - a drama school run jointly by Theatre Royal Plymouth and Plymouth University. However, it is the intention of the authors to provide material which can offer an insight into the generic audition process in other HE institutions. As such, these papers also draw upon the authors' own experience auditioning candidates for other drama schools, both in the UK and abroad, so as to uncover the various pedagogic, ideological and sociological functions of auditioning for training, as opposed to auditioning for an acting job.

This first article considers the initial 'first call' audition experience, so as to identify and to describe the stress-inducing aspects of the experience's design, and to chart how these aspects influence auditionees preparing them for study and training. This phase of 'first contact' between auditionee and institution can be understood via the dramaturgical exemplar offered in the first section of Stanislavski's writings and pedagogic discourse, An Actor's Work.

Part of this examination is concerned with reading the asymmetries of knowledge mapped within, and by, auditioning. More specifically, this paper is concerned with analysing the effects of the particularly theatrical dimensions of auditioning in inducing stress in students. This will entail delineating the social dynamics of this event and interpreting the effects of these on student experience. These social dynamics are manifest in the reconstruction

of the space of the 'theatron' within audition and are also operative within an economy of imitation, central to learning but which functions with a particular currency in the specific case of actor training in the Stanislavskian traditions. 
The analysis we offer of auditioning is addressed to that aspect of auditioning for drama school which comprises of the presentation of pre-prepared monologues by applicants. This is only one aspect of auditioning for drama school but is, in most cases, the first practical encounter that applicants have with a training institution.

Throughout this paper we quote from unstructured interviews we conducted with undergraduate acting students on this programme, and other vocational training programmes, as well as conversations with graduates of a range of UK drama schools. ${ }^{1}$

This article is concerned with analysing the social conditions of this particular stressful situation and their effects and not with making normative judgements about this event. The interpretations we make are not intended to be universally true but rather they can be seen to describe more than one student's experience, even if they do not account for all.

The participatory and observational method used to gather student perspectives on drama school training aims to expose the 'meaning' of phenomena by attending to the experiences of those individuals involved in it. We do not undertake to analyse the effects of ethnicity, age, gender, social status, etc on the attitudes of the applicants. While this may prove an interesting study in its own right, our focus has been on the attitudes manifested by the various individuals to which we spoke, specifically in relation to the stressfulness or otherwise of the experience of auditioning. Our concern here is with the experiential nature of that phenomenon, and the relationship of this to institutional practices, rather than the socio-cultural precursors and determinates for experiencing stress in individuals.

Like all phenomenological research the particularly enculturated perspectives of the researchers influences the analysis of the material gathered. In an attempt to give primacy to student experience, we will publish substantial quotations from our interviews and conversations with students throughout. In so doing we intend to show the basis of our interpretations whilst also leaving a space open for student experience to speak for itself, comparatively free from the pressure of our analysis. We are still, by necessity, selective in what information we choose to present but we hope that this method will preserve the integrity of the accounts we have documented. 


\section{STRESS}

'Stress', as a term associated with biomedical discourse on 'modern life', carries many negative connotations. Linking the pathologies of the 'stressed out' workers, executives and professionals of the contemporary moment with the pedagogies of Higher Education institutions is a politically fraught prospect.

That studying for qualifications entails a certain degree of stress is a commonly accepted fact but the possibility that stress might be a quintessential element, as opposed to a by-product, of education remains contentious.

The anthropologist Anthony Wallace was amongst the first to note the significance of stress in facilitating processes of personal and professional transformation back in 1961. His study of 'ritual learning' showed how stressful situations could bring about extensive and permanent cognitive and emotional changes and this phenomenon has, only recently, been definitively tracked in the stressful 'restructuring of behaviour' students undergo when training: for example, in training to become nuclear physicists (Gusterson 1996), psychiatrists (Luhrman 2001) medical doctors (Sinclair 1997) and psychotherapists (Davies 2008).

The historical period of anthropological scholarship that gave rise to Wallace's Culture and Personality (1961) and Religion: An Anthropological View (1966) was particularly fixated with the social experience of transformation. Victor Turner's writings on the ritual transformations occurring during rites of passage have been incorporated as a cornerstone of performance theory--by virtue of their arguments for a liminality decisively separating theatre from ritual; efficacy from entertainment (Schechner 1997 [2003]). That the 'rite of passage' transformations of the kind that have so fascinated performance studies occur under stressful conditions is a fact well established by anthropologists (Turner 1967; La Fonatine 1985; Herdt 1987; Davies 2008).

However, 'stress', in this article, does not solely denote the conventional usage of the term, being associated with unwanted, unjustified or unreasonable environmental pressures, but rather refers to a clinical definition: being an organism's total response to environmental demands ${ }^{2}$. Accordingly, the 'stressful situations' described do not denote 'bad practice' in drama schools but are rather examples of institutional and sector-wide conventions of practice. 
Whilst an important project is already underway in the work of scholars such as Mark Seton to develop guidelines for ethical practice in actor training, making suggestions towards these guidelines is not our intention here. Instead, we are concerned with highlighting the operations of stress at a particular moment in drama school training, and with examining how these stressful moments might be induced through the organisation of specifically theatrical conditions. Theatrical conditions associated with and modelled upon a specific form of realist theatre tradition.

As with Turner's notion of the processual transformation of a ritual subject through stages of displacement and re-aggregation, Wallace argued that learning functions in a ritualised context via, what he called, the 'law of dissociation'. Cognitive and affective 'restructuring' occurs through dissociation because the 'student' is radically dissociated from past knowledge before being brought into contact with new information.

According to Wallace, this kind of learning proceeds through phases. The first being pre-learning or anticipation. This is followed by 'separation', brought about by stress-induction, and then a phase of 'suggestion' wherein a subject is highly susceptible to suggestion, as in conditions associated with trance, conversion or possession. These phases give way to 'execution', to the attainment of a new cognitive framework and 'maintenance', through repetition and reinforcement. As with Turner's anthropology of ritual praxis there is debate over the continuity--or discontinuity - of processual sequence in Wallace's model ${ }^{3}$. Rather than view the stages of Wallace's model as discrete and sequential, this paper treats them as distinctly modulated conditions wherein, and during which, interpersonal and spatio--temporal dynamics are purposefully modelled.

In our analysis, we do not undertake to track chronologically the phases of Wallace's ritual learning model through a drama school training. Rather the emphasis placed by Wallace, and subsequent scholars, on stress in learning environments stimulates this enquiry into the social organisation of one stressful experience in that process. In our analysis of audition, we are especially interested in the conditions of separation and suggestion and how these might lead to the execution of particularly valorised skills.

Wallace's emphasis on the stressful experiences at the interface of past knowledge and future knowledge has directed anthropological scholarship on the experiences of training and learning towards giving prominence to institutionally ritualised initiations, and one might, of 
course, view audition as one such initiation. The psychiatrists Johannes Cremerius (1990) Arthur Kleinman (1988) have signalled the significance of the application of selection criteria to the training experience whilst the psychoanalysts Marguerite Valentine (1996) and Robert Hinselwood (1985) have tracked the relationship between such criteria and the 'fragmented community' of training institutions where 'schools' assert ideological ascendancy in opposition to others. Sensitized to the outcomes of these analyses, this article is an attempt to see what might be contributed to our understanding of these initiations through an interpretation of the particular example of the drama school and the specific experience of audition.

\section{KOSTYA'S AUDITION IN AN ACTOR'S WORK}

In An Actor's Work, Stanislavski offers no reflection over the audition process as such. In fact, there is no indication of the way in which students were selected to become part of the school that provides the milieu for all of Kostya's experiences of actor training. All we know is that the narrator of this fictive account (Konstantin 'Kostya' Nazvanov) worked as a stenographer in a lecture given by the actor, director and teacher, Arkadi Tortsov, and was so impressed by him that he decided to enrol in his school. It is in fact his ability as a stenographer (and his knowledge of shorthand) which allows Kostya to keep a faithful record of Tortsov's lessons (Stanislavski, 2017: 3). However, despite the lack of information regarding the school's admission process, the first chapter of this book ('Amateurism') discusses a number of events that function as an induction to the new students and which appear to mirror some of the phenomena that occur in the audition process.

In this section, Kostya and his classmates are asked to perform extracts from plays of their own choice in the main stage in front of leading members of Tortsov's company (Stanislavski, 2017: 4). Students are only offered help in technical matters (that is, in terms of set, costume, and make-up) but are not given any guidance as to how to perform or what is expected of them. To all intents and purposes, this group of (albeit fictional) budding actors are put in a situation which strongly resembles the audition process which HE students go through in the UK. It is highly significant that Kostya describes this process as nerve wracking and panic inducing (Stanislavski, 2017: 11-14), and noteworthy that this is the experience Stanislavski chooses to open his oeuvre. 


\section{FEAR OF REJECTION}

"The audition process is an abomination" (in Kohlhaas 2000:xi). These words, of the playwright, David Mamet account for a significant number of students we interviewed, including the student who gave us this account:

"I felt sick before going in [to audition]. I really wanted to do well but I was convinced that I had completely forgotten both my audition pieces. I felt thirsty but I also needed the toilet and the girl I was sat next to asked me if I was cold--I hadn't noticed but I was shaking!" ['Mary']

Mary's response is certainly towards the more extreme end of the spectrum of accounts we collected but it is not atypical in its description of the anxiety experienced in the minutes that immediately precede an audition. Even those who manifest less obvious outward signs of anxiety reported feeling disconcerted as they waited to enter the audition space:

"I was worried, for sure. Well, not 'worried', I mean I was confident about my [audition]

pieces but it's just that a lot is hanging on it, isn't it? I held it together, you've got to

haven't you but, I mean, I could be great but it's up to [the tutor], isn't it?" ['James']

One familiar psychological interpretation of this state of anxiety would associate these accounts with what is commonly referred to as a 'fear of rejection'. Fear of rejection can be seen to be intimately bound to its opposite; a desire for acceptance and the tension between these two possibilities perhaps plays a role in the generation of the stress reported by these two students. Rejection and acceptance can be seen to relate figuratively to openings; to exits and entrances, two activities which, in theatrical parlance, carry particular significance.

As a figurative point of opening, the audition is rife with both possibility and danger, and this microcosmic event reflects the macrocosmic reality of an ongoing training, such as is offered (typically over 3 years) in drama school. In Stanislavski's writings, entrances and exits, theatrical and otherwise, figure largely and, in An Actor's Work, Kostya's first 'induction' performance is deemed to be overall a failure so much so that when his shortcomings are explained to him he debates the idea of leaving the school altogether (Stanislavski, 2017: 35).

In a commentary on the actor and playwright Steven Berkoff's writings about his experience of "being rejected [for acting roles] so many times" (in Cross 2004: 76) at audition, Robert Cross draws attention to the 'opening' that is audition, understood as an interface 
between naïf and Establishment. In Berkoff's writings Laurence Olivier becomes a metonym for the theatre establishment that rejects Berkoff as a young actor.

Given the imaginative counterpoint Berkoff constructs between the Establishment and the outsider; Olivier and himself, and the "erotic mode of interacting" (Cross 74) he imagines between an "establishment [that] hates [him]" but "also loves [him]" (in Cross 75), Cross makes a double-entendre of Berkoff's wish to be 'entered' by Olivier. For Cross, the entering entailed in the sex act that dominates Berkoff's short-story Gross Intrusion--a story which Cross argues is "inextricably connected with Olivier" (ibid)--is paralleled by Berkoff's wish to be entered, "dybbuk-fashion by the spirit of his beloved 'Olivier"” (74).

Whilst it might be grossly distasteful to reference the sexual metaphor of Gross Intrusion given the young lives involved in drama school training it is not, on the basis of recent scholarship, grossly misinformed: Mark Seton's investigations into actor training in the UK have rendered some 'psycholinguistic' observations on the prevalence of "imagery... attendant upon loss of innocence, [and] a need for penetration" and the recurrence of themes of "vulnerability and seduction" (Seton 2010:5-6) in actor training.

This 'spirit' of Olivier is, of course, not so much the personae of this particular actor but rather the institutional character of the theatre establishment which he metonymically represents. The desire to be entered in the non-sexual sense is, perhaps, present in the drama school auditionee who seeks to be, if not possessed then perhaps entered by, and so embody, the particular skills associated with the drama school.

There is, of course, another sense in which the word--play on entering is informative here. The auditionee at drama school seeks to be entered into a programme of training and, in being so admitted, receive the validation of an establishment through training within it when, ultimately, he or she exits from it.

Whilst performing in general carries within it its own fears, often defined in catholic terms as 'performance anxiety' and in more discipline-specific parlance as 'stage fright', the drama school audition appears to operate a separate and significant stressor: Both students quoted appear to report what James Davies, in his study of the transformative conditions of psychotherapist training, calls "evaluative apprehension" (Davies 2008:23). This is a specific fear that one will be judged, as Berkoff feels he has been, unsuitable for a profession. 
One might want to argue that this fear is a component of stage fright more generally--indeed Nicholas Ridout has done much to show that stage fright might be "intimately connected with the specific condition of theatrical employment [emphasis added]" (2008: 9) ${ }^{4}$.

On the subject of waged employment, we can see that there are 'not-specificallytheatrical' reasons why a student at audition would experience stress. A 'fear of rejection' could be seen to be, as in other initiation rituals, a 'fear of incurring cost'. The drama school audition is distinct from many academic interview situations in the respect that it frequently carries a fee payable by the student ${ }^{5}$, although the students we interviewed did not pay such fee as such practice is not customary at Plymouth Conservatoire.

Just as with other significant stages of progression throughout the already costly and soon to be even costlier, experience of Higher Education, the audition induces what James Davies has called "understandable anxiety" about entering and progressing through training because "of the...economic and personal losses that any extension of training would entail" (2008: 54). This anxiety may be one aspect of the 'separation' experienced by students at audition but, on the basis of the reports quoted above, it would appear that in the immediate temporal experience of auditioning these anxieties are displaced or overcoded by the ritualisation of the event. Neither of the two students quoted above manifest any anxiety about the price of their audition. This student's stage-frightened condition might be seen to relate to the asymmetrical power relations mapped within audition, relations mapped upon the particular cartography of the theatre building.

\section{LIMINOID SPACES}

As Edward Soja has argued in his influential work, Thirdspace

"All social relations become real and concrete, a part of our lived social existence, only when they are spatially 'inscribed'--that is concretely represented--in the social production of social space. Social reality is not just coincidentally spatial, existing 'in' space, it is presuppositionally and ontologically spatial [emphasis as original]" (Soja 1996: 46).

To illustrate the argument, consider how social relations are 'concretely represented' in the spatio--temporal sequencing of auditions: our description here comes from the Acting 
programme at the Conservatoire but the events described are not dissimilar to those occurring at drama school across the country, and indeed the globe.

There is, by necessity, some form of green room or 'holding area' wherein students wait to audition. Having spoken to students who auditioned at a number of drama schools, and thus experienced various different versions of this area--from quiet, comfortable room to busy corridor--the relative comforts of this area appear to have little impact in salving feelings of anxiety. Several students likened their experiences in this area to experiences in a doctor's waiting room noting the minimal interaction between individuals and a feeling of uneasy silence. Practice for summoning applicants from a 'holding area' to the auditioning room varies but, in the Conservatoire, applicants are escorted personally by a student representative the, usually short, distance between the 'green room' and the audition room.

We tend to audition students either at Theatre Royal Plymouth, in the 'Lab' space underneath the main auditorium stage, or in one of our theatre studios. For ease, the tutor running the audition, will sit away from the entrance amidst a small row of chairs comprising a sense of audience. This use of space has obvious logistical benefits for the operation of a series of consecutive auditions but it also has the effect of thrusting the student straight on to the stage, as it were, from the moment they enter the door. This proximical arrangement places the student in a position to be viewed, assessed, judged before they have even begun performing; judged as a person, as well as latterly as the character they will play. Increasingly applicants seem to be aware of this; many are coached by drama teachers or private tutors to think about the whole time spent in audition as a part of the selection process and so often we will be confronted by a rather assertive presence emerging through the door and onto the stage space.

Several students we spoke with described the experience of entering the audition room as the most nerve-racking aspect of their audition and as the moment in which they felt most exposed. Two students specifically described entering the audition space through theatrical vernacular:

"As you come in it's sort of like, 'taking the stage' and you've got to recognise that you're performing from the moment you walk in" ['Paul']

"when I came in they [tutors] were sitting there and I felt like I'd entered from the wings" ['Maggie'] 
The theatre (or theatre like) space in which auditions are held appear to act, in Turner's words, as a liminoid space, a space which will provoke some sort of change in the participant after the event has concluded. In An Actor's Work Kostya is particularly concerned by being 'thrown' into the company's main stage. Thus, the audition space acts as a hallowed location which can be both desired and feared. In contemporary audition practices some institutions hold the first round of auditions in generic places and reserve their theatre locations for only those who progress to the second stage of their admissions process.

It is perhaps, in this act of 'separation' that audition processes can be related to the rites de passage described by anthropologists such as Victor Turner. The link to a numinous phenomenon may appear to be, at first, a simplistic reduction as auditions are clearly secular phenomena. However, Turner has famously argued that there is a myriad of contemporary ('modern') events that contain a kind of liminal quality (e.g liminoid) which share some of the characteristics of religious rites de passage (Turner 1990). Significantly, in most rite of passage 'neophytes' are separated from the larger population and put in a liminoid space in which the maximum authority is held solely by those who have been initiated (Turner, 1989: 47-49). In an audition, the prospective student is invited to 'peek' into the institutions' facilities and have a glimpse of the place that may become her future. In that place, normal rules of authority are suspended and all the power is concentrated in the members of the auditioning panel, whose judgement is final and uncontestable.

In the Conservatoire, we tend to sit behind a table, usually towards the edges of a theatre studio leaving maximal 'performance space' for the student auditioning. The table is necessary for holding piles of application forms and paper for note-taking but it may also operate as a barrier between tutor and student and, by facilitating the relative comfort of the tutor, emphasises the exposure of the student. We always remind ourselves, as tutors, to get up from the table to greet the student but the sense of objective distancing the table produces often returns as we give notes to applicants about their performance. Uncomfortable with the dynamic this setup generates, we have tried dispensing with the table. However, this usually makes us look rather disorganised with our papers that lay strewn about on tables and the floor and, furthermore, 
having spoken with students who came successfully through the audition process we have learned that many actually prefer the sense of formality that a table affords:

'well, I think it's good [that it's formal]. I want to know that they're serious about what they're doing, and serious about me.' ['Sarah']

'I wouldn't want it too informal. I want to feel like I'm being properly tested, properly observed. I respect that [formal distance] ('Leilani')

The dynamics of the gaze assembled between 'doers' and 'watchers' in the commercial proscenium theatre are emphasised here as they are stripped of their familiar adjuncts--no lights, no costume, no props, no fellow actors and even the modest comforts of the vertical relationship of dais to stalls is eliminated. This is Poor Theatre in an expensive context.

The tutor conducting the audition will normally, as a matter of procedure, be accompanied by a fellow tutor or student representative giving the auditionee the sometimes reassuring, sometimes anxiety-inducing sense of a mute audience.

"I was really nervous outside [the audition room] and I kept taking deep breaths to calm myself down. The auditions were over--running and so mine was late which meant that when I was called it felt a bit unexpected but it was a relief though. Going into the room was pretty daunting--it's that classic thing isn't it, with a table there and them [tutors] sat behind it. They were really nice though and told me to sit down and we chatted for a bit, which put me at my ease. When I stood up to do my [audition] pieces though, I got nervous again and I became really aware of him [the tutor] taking notes. I was thinking, 'is that a good note or a bad note?' and at the same time thinking, 'stop thinking about him taking notes and focus!'” ['James']

Auditionees are thus exposed to similar conditions than those experienced by actors who perform in the presence of critics, reviewers and agents and are asked to resolved a situation that even professional actors find distracting. In this respect, it can be argued that students who want to enter the Acting profession are required to navigate successfully a highly esoteric theatrical experience. The sequence of events at audition from the anticipation engendered whilst waiting outside the audition room--to say nothing of how this anticipation is modulated by the 'call back' or application process in general--to the 'exposure' of entering the space, the pressurised selfawareness associated with fear of distraction, and the apprehension entailed in the evaluative gaze constitutes a distinctly, and recognizably theatrical, spatio--temporally ritualized event. 
The interpersonal politics of the theatron--which are, of course, purposefully mirrored in the audition--envisage an imbalance of authority between "disembodied seer and blinded embodied actor" (Campbell 2001: 32) but, in their manifestation in audition they are over-coded by an implicit institutional hierarchy which maintains, not only power differentials, as in the theatron, but also decision-making responsibilities.

Stanislavski's famous description of the 'awful hole' of the auditorium in the first section of An Actor's Work assigns a 'power' to the audience-space and the fear-inducing public within it but, whilst the power of the 'awful hole' can 'posses' actors it cannot act institutionally to disbar them from a profession.

\section{INSTITUTIONAL EXPECTATIONS}

As was mentioned at the beginning of this article, this is intended to be the first part of a series of pieces discussing the audition phenomena. It is expected that a later contribution will examine the way in which auditions stand as an archetype for an experience of self-adjustment whereby actors align (and misalign) themselves with commercial and ideological values, and the ways by which institutions cause these alignments and misalignments, both knowingly and unknowingly. However, the next section will begin to discuss some of those acts of self-adjustment as the main axis of this article is centred on the auditionee's experience and one of the key aspects of this experience is the heightened sense of uncertainty as to what, precisely, is expected from them.

In other words, auditionees are judged against criteria that remains diffuse and mysterious and are virtually powerless against the judgement exercised over them. In this respect, the 'abominable' casting audition, for example, clearly contains an acutely unequal distribution of agency since it can, in one sense, produce a judgement not only on an actor's suitability for a specific role but also on an actor's abilities per se. However, the significance of the casting decision is intensified in the drama school audition wherein a judgement is primarily being passed on an individual's suitability to enter a profession, and where that judgement will have a primary and wide-reaching impact on an individual's professional prospects.

The drama school audition is both emblematic of auditions in general and at the same time an intensification of the politics organised within auditions, and within theatre itself. Its situation at the 'beginning' of a career endows it with a particularly acute relevance to the 
professional development of an actor. As a point of interface which can lead to either rejection from, or absorption into a professional knowledge community, the audition possesses the characteristic attributes of a stressful separation phase of experience. In our observation of auditions tutors show a high degree of awareness of the stressfulness of this situation for students and frequently act to counter this by attempting to disrupt the passive-active actor-audience dynamic with personable conversation.

The capacity of each student (and tutor) to manage their own actions under these stressful conditions undoubtedly varies from person to person but the evidence of our observations suggests that, within a range of individual responses, the ontological-spatial organisation of the event preserves a certain common utility even as it is differently experienced by individuals. This, perhaps, relates to what Wallace calls the 'suggestion' phase of ritual learning.

"I was half way through my [second] monologue and he [the tutor] stopped me. He said that I was playing both monologues at the same, sort of, pace and asked me to try to respond to an image in the text -- it was my Shakespeare [audition] piece and it [the image] was Lady Macbeth saying ‘unsex me now' -- and speed up a bit. So, I really tried to take what he'd said on board and started again trying to pick up the pace a bit" ['Paul'] At audition, a tutor will almost invariably 'give notes' to a student. That is to say, students will be questioned about the choices they are making in performance and may have an alternative 'choice' suggested to them.

Some critics might choose to see this as an attempt to ascertain a student's ability to 'take direction'. In the commercial theatre environment, populated by talent and casting agents, into which drama schools aim to induct their graduates, a model of the actor-director relationship exists which many contemporary theatre-makers might view as 'traditional'. Without wanting to stereotype this commercial theatre environment, an actor's ability to absorb directorial criticism and respond practically, and swiftly, to it by adapting her performance remains a valued skill herein.

It might be tempting to read this aspect of audition as an experiment in obedience: The particularly theatrical dynamics of the audition establish the tutor as an authority figure, as a legitimated symbol of the training institution and a person in whom the will of that institution is manifest. However, interpreting the practice of 'giving notes' in audition as simply an exercise in assessing an individual student's ability to yield to authority would be to take a rather simplistic 
view. 'Giving notes' can also be seen as a way to assess a student's flexibility, versatility or 'range' and their capacity to incorporate new ideas and alternative ways of working. It can also be seen as a way of assessing a student's communication skills and ability to listen. Whilst it might be overly-simplistic to view this practice as a means of testing a student's capacity for subjecting themselves to authority it is worth noting that, in the numerous auditions the authors have attended and in all the accounts from students we have collected, we have yet to come across an example of a student refusing to absorb the criticism they were offered. Whilst students are invited to question, or rather, seek clarity, with respect to what they are being asked to undertake when they are being given notes - and it should be said that we have observed a number who have done just that - we have yet to encounter an instance of a refusal to accommodate a tutor's request.

As Howard Becker has argued in his book about medical training, Boys in White, the social organisation of training assembles institutional expectations, which students must 'read' and 'respond to' in order to succeed. In the event of audition the capacity to read these expectations and the imperative to respond to them is intensified by the distribution of decision-making responsibilities and the mapping of these within an interpersonal dynamic between 'seer' and 'doer'. As James Davies, in his paper on the training of Psychotherapists notes, in training, "conflict avoidance often guides students' behaviour by communicating far more clearly than overt pedagogical demands in what direction as novices they [students] are to strive to succeed" (Davies 2008: 50). Feelings of exposure, evident in the descriptions of audition published thus far, can lead to the conscious suppression of behavioural traits; the kind of restraint we perhaps all try to practice in interview situations -- not mumbling answers or rambling on, not being clumsy or seeming shy or nervous. The extent to which this conscious suppression was a problem for candidates in interview situations before widespread knowledge of 'body language' is a moot point, especially in the particular 'interview' situation of an audition where those auditioning are making conscious praxis of unconscious para--praxis in their representations of characters.

In this limited sense, imitation is key to success at drama school audition. Imitation, or rather mimesis, is of course central to a UK drama school training in general, which is largely modelled around acting theories associated with a theatre of 'realist' verisimilitude. Precisely what is entailed in mimetic labour --i.e. whether it is 'imitative' or 'productive' (Kear 2005)-- is 
a complex issue but, as Jerome and Julia Frank have indicated, imitation, in a quite literal sense, might be central to the experience of learning itself. They argue that a trainee's dependency on a supervisor's guidance and approval disposes them towards 'imitating' tutors' values,

perspectives and judgements (1961: 195). Such imitation, or 'modelling' as they call it, has been shown to be a powerful didactic mechanism in learning, especially of children (Bandura 1977) and it is specially modelled in audition.

Whilst tutors might assert implicitly the worth of the craft of acting through audition, in the practice of 'giving notes' they also function as what James Davies has called, the 'embodied answer' to the question 'what do trainers want?"' (2008: 60). Once again, An Actor's Work offers us a meta-example of some of the underlying conditions present in an audition process. In their 'inductive performances' (as mentioned above) Kostya and his classmates present work which is deemed to be largely unsatisfactory and which 'demonstrated [...] what you must never do on stage and what you must avoid in the future' (Stanislavski, 2017: 38). Tortsov uses that work to describe the kinds of acting that differ from his approach (which he terms representation, stock-in-trade, ham and exploitation) but also signals two brief moments that come close to the style of acting that he is after ('the art of experience', 2017: 37). In audition, where the precise requirements to be met by auditionees might be only dimly perceived by them, the giving of notes appears to answer this most fundamental question; 'what do trainers want?'. The student's capacity to imitate said 'embodied answer', through reflecting the values and attitudes they appear to express, can act as "a palliative for 'evaluative apprehension' and its associated fears" (Davies 2008: 60).

Giving notes can entail identifying for auditioning students those aspects of their performance which reflect, and those which conflict with, the expectations of the particular training institution. Notes can suggest alternative choices but can also reinforce existing choices.

"she [the tutor] told me that I had a 'lovely soft quality' to my speaking voice that worked well with one of my pieces but which wasn't as well suited to my other monologue. That gave me a lot of confidence in my first piece. She suggested I do my second monologue again with this in mind. I'd never really thought about that but, once she told me, I started to notice it more and now I'm more mindful of how I should be using my voice in different roles" ['Leilani'] 
It is well known that approval is crucial to educational progress not only because of its motivational effect but also because without it, as James Davies puts it, "self belief might be experienced as illegitimate" (2008: 60).

The above account is typical of those we collected in that it indicates that students trust tutors, especially in the quintessentially evaluative exercise of auditioning, to recognize and classify weaknesses (and strengths) in their performances, which may not be entirely clear to students themselves. Furthermore, students trust tutors' proposed remedial advice.

The matter of whether a student genuinely perceives a 'problem' identified by a tutor or whether they simply respond to the suggestion that there may be one is a particularly fraught question when thinking about training through Wallace's conditions of separation and suggestion. Taking any normative judgement on this dilemma is beyond our remit here but it is raised in order to draw attention to a particular characteristic of the operation of 'stress' in training: James Davies writes that, during training in an educational setting, students, "quickly learn that they are judged on something more intangible, less quantifiable than 'examination performance'--namely, on what can be experienced as a vaguer kind of 'suitability' as defined by those socially positioned as responsible for adjudication" (54)

Indeed, in assessing accounts given to us by students, the analytic judgements communicated to students during audition, and throughout training, can be understood by them as akin to divinations of their future prospects, both in the institution and beyond. As Davies writes, what constitutes such 'aptness'--the student's 'traits' or 'behaviours' as distinct from their academic results--“might remain a mystery to many trainees until they are informed about how they are perceived by their seniors" (ibid) and, in the dilemma outlined above, they may of course remain mysterious even after this information is received.

In summary, audition can be seen to develop high anticipation, dissociating students from their pre-existing knowledge and attitudes and rendering them susceptible to suggestion. It might appear that evaluative apprehension is an aspect of all forms of assessment but it would seem that the separation accomplished in audition, and the susceptibility this induces, can be seen to result specifically from the inscription of specifically theatrical relations in space. Furthermore, in HE contexts that offer an Acting pathway those theatrical relations are often specifically associated with a realist theatre tradition as the preparation of actors in the sector is still primarily 
associated with the teachings of Stanislavski. In that respect, Stanislavski's writings can offer us a number of interesting insights into the contemporary process of auditioning.

Auditions also instigate a complex interplay of power differentials that raise challenging ethical issues which need to be considered in depth by those in charge of these processes. The status of the tutor within audition as not only a legitimated authority figure but also an image of future possibilities; the realisation of the answer to the question, 'what will I become as a result of training?' has an influential effect on stressed auditionees, rendering them open to suggestion. This analysis of the operation of stress in drama school audition might show that auditioning is not only - and perhaps, not even - about assessing skills but is also about ensuring the reproduction of institutional values. As such, in conditions of high stress and susceptibility, HE institutions might be privileging the student's ability to read and reflect institutional expectations embodied by the tutor rather than gauging the student's enthusiasm and potential, or indeed their possessions of the rather more ineffable qualities of 'talent'.

However, before continuing to probe the relationship between auditionees and institutions, it might be necessary to recognize that prospective students are not a tabula rasa and come to these processes with distinct knowledge, degrees of preparation and expectations of that which they might experience. As such, in the second part of this series we aim to investigate how the interconnection between character and self-identity - encountered by auditionees in prior training and study - provide the potential basis for self-identification between the auditionee with the auditioners and, by proxy, with the institution. 


\section{Sources}

Battestin, M. C (2000) A Henry Fielding Companion, Santa Barbara CA: Greenwood Publishing Group

Braxton, J.M. (2008) 'Towards a Theory of Faculty Professional Choices in Teaching That Foster College Student Success' in Smart, J.C. (ed) Higher Education: Handbook of Theory and Research, Vol. 23, New York: Springer, pp. 181--208

Counsell, C. (1996) Signs of Performance: An Introduction to Twentieth Century Theatre, London \& New York: Routledge

Cross, R. (2004) Steven Berkoff and the Theatre of Self-Performance, Manchester: Manchester University Press

Delgardo, M. (2008) Federico Garcia Lorca, London \& New York: Routledge

Frank, J., \& Frank, J., (1993) Persuasion and Healing: A Comparative Study of Psychotherapy, John Hopkins University Press ( $3^{\text {rd }}$ Edition).

Frankenhauser, M. (1986). 'A psychobiological framework for research on human stress and coping' in: M. H. Appley \& R. Trumbull (eds) Dynamics of Stress: Physiological, Psychological, and Social Perspectives, New York: Plenum Press, pp. 101--116 
Frankenhauser, M. (1981) 'Coping with stress at work' in International Journal of Health Services, Vol. 11 pp.491 - 510

Handelman, D. and Lindquist, G. (2005) Ritual in its own Right: The Dynamics of Transformation, Oxford: Berghahn Books

Hinkle, L. E. (1973). 'The concept of stress in the biological social sciences' in Stress Medicine and Man 1, 31-48

Kear, A (2005) 'Troublesome Amateurs: Theatre, ethics, and the labour of mimesis',

Performance Research, 'On Theatre', Vol. 10 No. 1, London: Routledge, pp.26--46.

Kohlhaas, K. (2000) The Monologue Audition, London: Nick Hern Books

Levi, L (1984) Stress in Industry: Causes, Effects and Prevention, Occupational Safety and Health Series No. 51, Geneva: International Labour Organisation

Merlin, B (2016) Facing the Fear: An Actor's Guide to Overcoming Stage Fright, London: Nick Hern Books

Pike, K.L. (1967 [1954]) Language in Relation to a Unified Theory of the Structure of Human Behaviour, The Hague: Mounton

Rodenburg, P. (2002) The Actor Speaks: Voice and the Performer, Basingstoke Hampshire * New York: Palgrave MacMillan

Seton, M. C., (2010) 'The ethics of embodiment: actor training and habitual vulnerability' in Performing Ethos, Volume 1, No. 1, pp.5-20.

Schechner, R. (1997 [2003]) Performance Theory, London \& New York: Routledge

Stanislavski, K. (2008 [2017]) An Actor's Work, London \& New York: Routledge Turner, V. (1990) ‘Are there Universals of Performance in Myth, Ritual and Drama?' in R. Schechner (ed) By Means of Performance: Intercultural Studies of Theatre and Ritual, Cambridge: Cambridge University Press

Turner, V. (1989) 'Betwixt and Between: The Liminal Period in 'Rites de Passage'” in: A. C. Lehman, \& J. E. Myers (eds) Magic, Witchcraft and Religion: An Anthropological Study of the Supernatural, Houston: Mayfield Publishing Company Zucker, Carol, (1999 [1951]) In The Company of Actors, London \& New York: Routledge

\section{Web sources}


NCDT (National Council of Drama Training) 2009, Guide to Training, Courses [online]. Available from http://ncdt.co.uk/guideto training/courses. [accessed November 2009)

${ }^{1}$ It is not an aim of this paper to determine any 'trends' occurring across undergraduate levels as students reflect on the experience of audition and so subsequently we do not identify students by their undergraduate level.

2 This definition comes from a tradition of research into the concept of stress in the biological and social sciences (see Hinkle 1973). As Frankenhauser points out, 'research on human stress...is the meeting place for a number of disciplines' (1981: 213) each of which proposes a distinct perspective on the concept. However, Levi's suggestion that stress 'refers to a process in the body, to the body's general plan for adapting to all the influences, changes, demands and strains to which it might be exposed' (1984: 1) provides something of a unifying theme for this research and offers the sort of 'clinical' definition to which this article refers.

${ }^{3}$ Handleman and Lindquist take a relevant stance with respect to this debate arguing that ritual, could be conceptualised as neither a continuation nor a suspension of normative social codes but rather a deceleration of the structurating processes of everyday living in the midst of those very processes, which engages the "tempo and dynamics" of these processes and opens them up to modulation $(2005: 48)$

${ }^{4}$ Bella Merlin has recently published an extensive analysis about the stage fright phenomena where she argues that it is caused by numerous internal and external elements (Merlin, 2016). We recognize that this is a complex topic and cannot be reduced to the potential judgment related to enter and/or remain in the Acting profession. Nevertheless, we believe that a key aspect of that fear contains (or leads to) a suitability judgment. Significantly, in the introduction of her book, Merlin finishes her description of one of times when she experienced stage fright by wondering if she would ever get a job again.

${ }^{5}$ It is important to note that not all students are liable for this fee: some drama schools offer exemptions on the basis of (family) income. 